\title{
The Influence of Technoethics on Industrial Design
}

\author{
Zhong Fan ${ }^{1, \mathrm{a}}$, Yanming $\mathrm{Ge}^{2}$ \\ ${ }^{1}$ Lecturer, College of Design and Innovation, Tongji university, China \\ ${ }^{2}$ Lecturer, College of Design and Innovation, Tongji university, China
}

\begin{abstract}
Technoethics is an interdisciplinary research area that means ethics in technology. Technology is transformed into the products in our daily life by industrial design and the negative effects of technology abuse makes ethics issues cannot be ignored. But design ethics research rarely from the perspective of technoethics, which is worth reviewing and summarizing. This review focused on the influence of technoethics on industrial design in the context of technological development. Through studying technoethics and industrial design from the 19th century, we find they have similar developing processes and the early 20th century and 1970s are two key point in time. This article aims to present the development of technoethics and industrial design intuitively on a timeline to discuss the impact on industrial design from the perspective of technoethics.
\end{abstract}

\section{Introduction}

\subsection{Definition}

Technoethics means ethics in technology and it could be found in Dewey and Peirce's pragmatism firstly. The term "technoethics" was coined in 1977 by the philosopher Mario Bunge in order to describe the responsibilities of technologists and scientists to develop ethics as a branch of technology.

\subsection{Background}

The development of technology has revolutionized our way of life, but it also brings serious problems of population, social problems and environmental problems. In the face of increasingly severe demographic, social and environmental issues, ethical dimensions are becoming very important. According to the results of the sixth China census, November 1, 2010 China's population aged 60 years and over reached 178 million, accounting for $13.6 \%$ of the total population. The growth of modern industry since the late 18th century produced massive urbanization and the rise of new great cities in other regions as well as Europe, as unprecedented opportunities brought enormous migrants from rural communities into urban areas.

\footnotetext{
${ }^{\text {a }}$ Zhong Fan: fanzhong@tongji.edu.cn
} 
In general, environmental impact comes from (excessive) consumption of natural resources and emissions of pollutants to air, water, and land [1]. The emergence of great factories and the concomitant immense growth in coal consumption gave rise to an unprecedented level of air pollution in industrial centres; after 1900 the large volume of industrial chemical discharges added to the growing load of untreated human waste [2].

In the context of technical intelligence, technoethics is becoming more and more important, especially the artificial intelligence and robotics communities facing an important ethical decision [3]. Repetitious work is being replaced by algorithms that control databases and robots. The scope of these algorithms continues to expand. There are arguments about the limits of machines, but it is fair to say that machines cannot currently perform "creative" tasks [4]. However, robots may always have limitations on perception, cognition and actuation. There are still hurdles to overcome to enable robots and humans to co-exist safely and productively [5].

Technoethics enriched the meaning of technology. Recently, many instances in the world culture are pushing towards the rediscovery of the ethical dimension of technology [6]. As the inherent dimension of technology, ethics has evolved with the development of technology. Technology demanding for ethics is the inherent requirements for itself, and it mainly manifested in three aspects: First, the quality of technology is ultimately tested by nature and technology should be harmony with nature. Second, the freedom of technology determines the technology must be self-discipline. Third, ethics intentionality of technology is pre-existence comparing with technology practice. Therefore, the ethical dimension is the inherent dimension of technology, and the demand for ethics is the inevitable requirement of technology developing [7].

Technology is the critical factor in the industrial design. Industrial design originated in the era of industrial civilization and the root cause is the mechanized mass production and the division of labor by the industrial revolution in the West [8]. From steam rea to digital era, technology is the main driving force for social development and is the main service role for design. In the field of design itself, technology also has made great revolution in design process, like Computer Aided Design. Digital technologies are influencing the way that design project work and practical studio work are taught [9]. Neil Gershenfeld argues that digital fabrication is being regarded purely in terms of conventional thinking as an additional production process by many engineers and designers and one of the intellectual frontiers associated with the development of digital fabrication is the development of an associated design theory [10].

However, at present, most of research about design ethics does not involve technoethics issues. In the context of technology-based service development, design encompasses those elements of the development process which enhance and communicate the value of services [11]. Design is the process of trying to make the world friendlier to us clumsy humans; it is the effort to make the world more caring toward us, more accepting of us and so more morally acceptable to us [12]. The questions raised for ethics by the objects of technology are defined by the major areas of their impact and thus fall into such fields of knowledge as ecology (with all its biospheric subdivisions of land, sea, and air), demography economics, biomedical and behavioral sciences (even the psychology of mind pollution by television), and so forth [13].

\subsection{Motivation}

Technology is the key factor in industrial design, while the development of technology is also critical factor in our social progress. But the energy crisis of the 1970s allowed us to realize the negative impact of blind pursuit of technology and some philosophers began to discuss the ethics issues of technology. Of course, this crisis has spread to the field of industrial design and designers began to think about the value of design. In particular, Victor Papanek referred to the design ethics for the first time in 'design for the real world'. However, there is little literatures has discussed the relationship between technoethics and industrial design. In our review study, we focus on the influence of technoethics on the industrial design to do this literature review. 
In this section, we discuss the definition of technoethics and why we try to do a literature review exploring the influence of technoethics on the industrial design. In the coming section, we explain the methods of filtrating the literatures and analyzing them. Subsequently, we will sort out the development of technoethics and the impact of industrial design in accordance with the timeline. Finally, we will discuss and summarize the information obtained from these literatures.

\section{Methods}

In this section, we try to present the method we have followed in research to conduct the literature review. We begin with the illustration about how we selected the articles on which we based the literature review. Then, we describe how we analyzed the articles by drawing on the historical timeline of the information.

For our review, we have selected thirty journals from three important databases, which were Elsevier, JSTOR, IEEE using keywords "technoethics", "philosophy of technology", "history of industrial design" and "design ethics". There are three main aspects of the literature: "technoethics', 'the history of industrial design' and 'design ethics'. At the same time, in order to have a comprehensive systemic understanding of technoethics, we have read the important chapters of six books briefly.

After review many technoethics and industrial design articles, we find technoethics and industrial design have similar processes and there are two critical points in time that they both had great changes. Finally, based on the outcome of above, the detailed analysis and findings are as follow.

\section{Analysis and Findings}

The history of industrial design is not long, it formed after the human into the industrial civilization gradually, and the mechanized large-scale production and division of labor from the modern Western industrial revolution is the root cause of its appearance [8].

So in this section, we divide out three times, with two key points, and each part has been described based on the technical background on the technoethics and its impact on industrial design. After that we briefly outlined the situation today with the same structural approach.

\subsection{In the 19th century}

Europe's industrial revolution is an important turning point in human civilization in the 18th century. It is a sign that the Western world truly enters the capitalist society from feudal society and the beginning of human civilization from the era of industrial civilization. This revolution is the most direct cause of industrial design [8].

At the end of 18 th century, the invention of the steam engine marks the era of human civilization into 'the steam power era', and then appeared in the factory, steam locomotive and the British became the first industrial country in the world. In the 19th century, with the discovery of electricity, manufacturing and processing and people's lifestyle have undergone a radical change. With inventing telegraph, cable, telephone, electrified railway and then to the production of electricity, electricity began into people's daily life from the factory. Electricity era is a more efficient and more convenient than the era of steam.

The great changes brought about by the industrial revolution have had an unprecedented impact on the design field. At the same time, the traditional artisans have no way to keep up with the increasingly complex product technology issues. However, the serious disengagement of new technology and art has become the most important and most acute contradiction in the field after the outbreak of the industrial revolution. In this context, the early industrial design was born. 
The outbreak of the First World War in 1914 lasted for four years and 1939 to 1945 the Second World War broke out. These two World War have brought destructive blows to mankind, and social development has been stagnant. But their strong demand for new technologies and materials has allowed technology and industrial design to develop unparalleled.

At the beginning of the 20th century, the standardization consciousness was based on the national scope, and some industrial powers established standard institutions to publish production standards. In 1902, the British established the 'British Engineering Standards Association, and later developed into 'British Standards Institution'. In 1916, the German Standards Commission was established. In 1918, the American Standards Association was officially established with the support of Hoover.

In the aspect of materials, steel die technology was used to manufacture the shell of household appliances. Followed by refining pure aluminium technology and electricity become cheap, allowed aluminium products began mass production. In addition, the more important material is plastic discovered in 1869 in American, and from the 1930s it was widely used in product design and the technical civilization went into the plastic era.

In this period, technology theory has begun to develop, and the most important theory is the technology determinism by Thorstein Veblen. 'Technology marches in seven-league boots from one ruthless, revolutionary conquest to another, tearing down old factories and industries, flinging up new processes with terrifying rapidity.' [14]. In the middle of the 19th century, the development of new technologies was growing rapidly, but the problems of mechanization and the marked decline in product quality were more and more prominent.

From 1810 to 1897 , the usage of the word "design" declined. After 1897, it increased-and notably so after 1936 and again after 1967 [4]. Just this period happens to be the beginning of the modern movement in the history of design, after the industrial design into the unprecedented prosperity. Almost all of the basic ideas of industrial design, methods and its role in the socioeconomic development are formed in the twenty years after the First World War.

In this period, the impact of technical and philosophy of technology on the industrial is to make rude new technology elegant and to find the right way to visualize the products. And the second aspect is the change in the way of manufacturing has had a profound impact on industrial design, which is the core of the manufacturing standardization. Ford T-car is the success of automobile production standardization model in the beginning of the 20th century. The establishment of standardization is the inevitable result of the change in the way of production, but for the designers it also means that the new product aesthetics and the corresponding design language changes.

Der Deutsche Werkbund was established in 1907 and its core was 'quality'. They were actively concerned about the progress of new technologies and product design related to the invention and maintain an unprecedented industrial spirit. Peter Behrens designed Turbine Workshop was the closest to modern architecture and he designed a fan for general companies as a model of functional and technical unity. In 1914, the result of Cologne debate was that the historical development is not to avoid or reject the inevitability of technology, but how to grasp and transcend. In 1919, Weimar Art Institute and Weimar Arts and Crafts School merged into Der Staatliches Bauhaus, and Walter Groupius as its principal. Bauhaus laid the foundation of modern design education and was also the main force of modern movement. They argued that technical and artistic barriers should be eliminated and design aesthetics designed to adapt to new production methods and technical levels. The products designed should reflect the technical characteristics of the production mode.

A typical example is the famous S-shaped steel pipe cantilever chair designed by Brewer in 1928. The structural relationship between the steel pipe material is developed in the form of largest simplified. In addition, there are Teague designed Bantam Special camera for Kodak and Alto designed bending wooden chair by steam bending forming technology. They all tried to unify aesthetics and technology to express the characteristics of new technology. They thought handicrafts were only the means to reach the target, and the role of industry was the basis for future production [15].

In this period, technology was developing rapidly and designers helped create a lot of new products without hesitation. We invented and designed a large number of products and all kinds of new materials and new products appeared every day. Unprecedented prosperity in the areas of 
industrial and industrial design covered up the possible negative crisis. May be due to mechanized large-scale production has not yet shown a negative impact in the short time, the mainstream of technical philosophy theories still focused on the technical determinism theory.

\subsection{In 1970s: The second key point in time.}

After the Second World War, the economies of Europe began to recover, especially in the 1960s, when the economic development of the capitalist world entered a period of victory. On the on hand the benefits of industrial production methods have been the greatest degree of expression, on the other hand, all the crises of industrial civilization in this golden age began to appear. In 1950s, Planned Obsolescence in the rise of Detroit Motor City supported that the life of the product should be limited, or by reducing the durability of the use, or making it quickly out of style to stimulate consumption. This decision completely ignored the serious consequences of large quantities of material energy consumption, especially after the 1970 s energy crisis it had been criticized widely.

In 1970s, capitalist world suffered a recession and energy crisis, while the blind pursuit of efficiency has brought serious ecological environmental problems. The manufacture of goods themselves is increasingly automated. Labor costs in the 1970 s were a major consideration in factory location. That has declined as factory automation has expanded [4]. Since then, the protection of the ecological environment has become the important subject to all the mankind.

In 1970s, there is a clear shift from philosophy of technology to technoethics in the European and American philosophical area [16]. Most Western philosophers argued that the cause of the crisis was caused by technological progress and the expansion of technology to the social sphere of life that did not belong to it. The most notable feature of product manufacturing in this period was the busy expansion of production to meet the growing social needs. These problems have gone beyond the scope of traditional technical philosophy and entered the moral time category. What is morality in this era of technical decision? Hu Ning argued that technology and technical creation should serve the culture as a living condition of man and the peace in the world.

On the other hand, Wanda Orlikowski has studied the duality of technology: objective and human aspect of technology. The identifies prior views of technology-as either objective force or as socially constructed product-as a false dichotomy [17]. He thought technology is the product of human action, while it also assumes structural properties. So facing the technology issues, we need to do a strategic choice, that is we should consider the human aspect of technology not limited in the technology determinist.

The whole society should be careful to consider saving energy, maintaining ecological balance and control of economic issues, and industrial design made the most direct response to this. In this era of design theory began to become more diverse. Emerging design areas began to appear, like green design, universal design, sustainable design and high touch design.

The design of this era had been adapted to the new technology processing context. The focus of the design from the fashionable style of the shell wrapping new technology developed to pay more attention to the use of rationality and comfort issues. As technology philosophy turned to technical ethics, industrial design began to consider ethical issues. The most representative is the book 'Design for the real world', published by Victor Papanek, which marked the design ethics appeared. He criticized the reality of design was a commercialist vassal and called for the design required a sense of social morality and needed A Return from Form to Content.

At the same time, design for the human needs also began to specialization, systematic direction. Design for the old people, for the children, for the disabled and the universal design had been carried out in-depth research. Universal Design was coined by Ron Mace (1998) to reflect a type of design allowing all users to be accomodated [18].

Some of which are difficult to promote in the business community because of the special needs of the clients, but they must exist in our society. Erik Herlow mentioned in the 1970 Swiss Environment Discussion and Action Foundation that designers needed an ethical attitude and designer transformed 
the industrial design into a medium for mass consumption, mass production, and mass consumption. Design would be either a means of self-destruction or a tool for survival in a reasonable world.

\subsection{In the 21st century}

Mankind enters the 21 st century, we have entered the digital and intelligent era. Over the last ten years there have been major digital advances in technology that have the potential to significantly change practice in Industrial Design. These include but are not limited to: Improvements in access to the internet worldwide - the expansion of the network, increased band width, improved communication tools supporting sophisticated interactions between designers, production companies and consumers. Advances in scanning technologies and the software to manipulate point cloud data. Developments in the use of RFID chips and the creation of digital tools to support an internet of things approach. Advances in additive manufacturing to include the use of metals, functional polymers and ceramics [10].

The lines between Industrial Design and digital design are blurring, just as is happening in other disciplines such as Graphic Design, Architecture, Forensics and a myriad of others. Digital technologies are disrupting the boundaries and academics and designers can respond positively or work against it [10].

\subsection{Results}

We use the timeline to sort the trivial information below as followed in table. 1

Table. 1 Historical Timeline

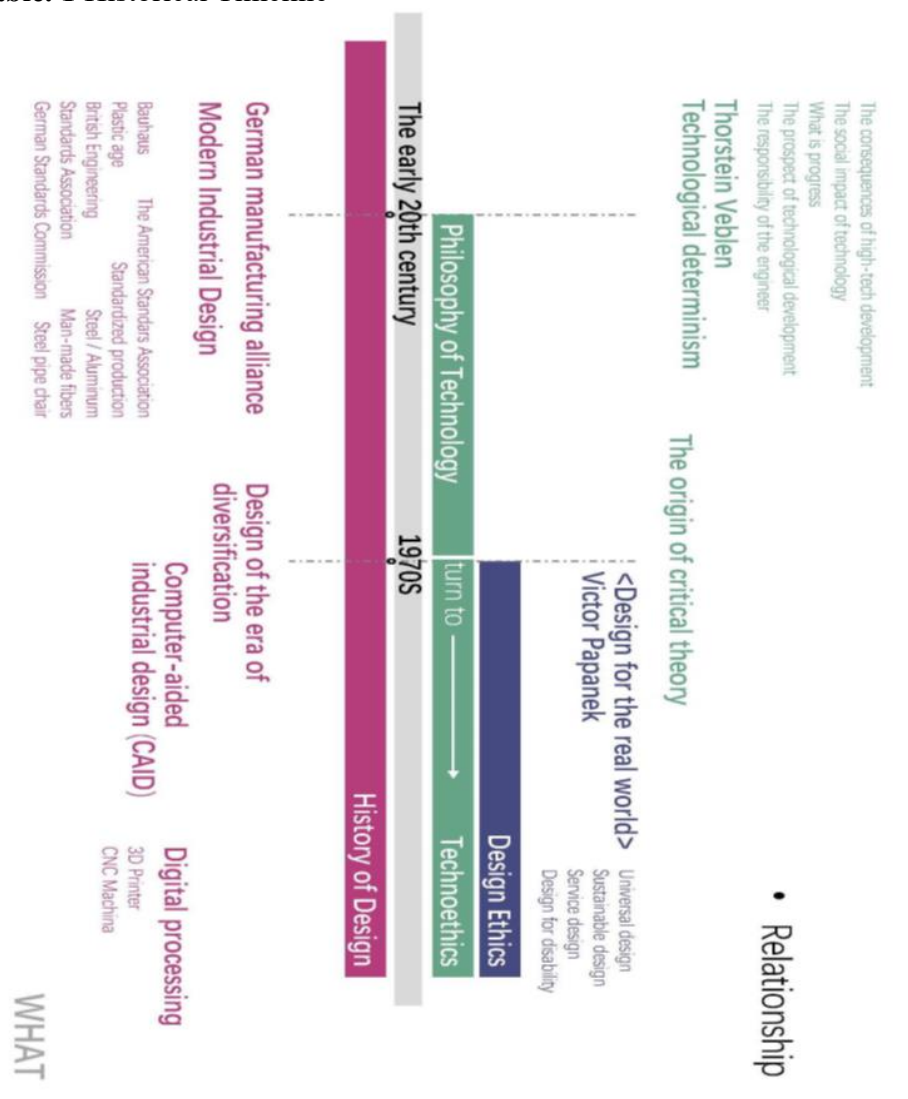


It is difficult to predict where technological innovation will take designers, how it will impact users' lives [10]. But from the human history process, the essence of the design is to reflect the good people to make technology and other material forces to achieve the value of improving human life [8].

\section{Discussion and Conclusion}

Based on the findings stated above, the following issues are worthy of further discussion. Machines are proficient, useful, timesaving, and labor-saving, but they are monotonous and lacking imagination. The ability to recognize two-in-one is the substratum of the human imagination, a thread running between art and design and everyday life. As a body extension of the machine, replace the work of people step by step. It underscores a more general proposition: the work of the future will have to be more imaginative, or else it will be turned over to machines [4]. Ethics has always been associated with human-to-human relations. Products, artefacts, built environments, communications, have only entered the ethical domain as tangential, and therefore neutral means, used by humans in their relations to other humans. To date, things, designed things, have not assumed a central or at least symmetrical, role with humans when it comes to ethics [12].

Technoethics and industrial design have similar developing processes. In this review, we can find this conclusion. In the period of blind worship technology, technical theory was one-sided, and industrial design was also not aware of ethical issues and recognized their own value in the process of technological development. Until 1970s, the ethical consciousness began to awaken. Philosophy of technology turned to technoethics and design ethics appeared to be independent from industrial process. Since then, the role of people has become increasingly heavy, and the two theories have begun to become three-dimensional pluralism.

Technology is the critical factor in the development of technoethics and industrial design. By convention, we judge a design by its functionalist and technoethics has developed based on negative issues from the progress of technology. Besides, technology revolution is the key power in the change of design.

The duality of technology: Objective reality (Deterministic Role) and Socially constructed product (Strategic Choice). In this process, the role of industrial design is the human who chooses what to do and how to realise it. After 1970, the beginning of the theory of technical criticism, the duality of technology, technoethics and to the ethics in the design field, they all due to put the human factors into the original reckless development considerations. In the process of industrial design, we need to make a strategic choice of materials, manufactories, new technologies.

Industrial design is a bridge between people and technology in modern society, and the material basis of industrial design is modern science and technology [8]. Industrial design will truly transform the new technology into human production practice and material products in our daily life, and it naturally becomes an intermediate link between the needs of human and manufacturing as the product of the division of labor. Technology represents only the possibility of substance, so that we need the power from design to make it really become part of the field of life. Design is the process of trying to make the world friendlier to us clumsy humans; it is the effort to make the world more caring toward us, more accepting of us and so more morally acceptable to us [12]. On one hand, the purpose of design is to guide the new technology to provide service for people, on the other hand the design continues to put forward new developing needs to technology. 


\section{Reference}

1. Bras B. Incorporating environmental issues in product design and realization[J]. Industry and environment, 1997, 20(1): 7-13.

2. Fleming J R. Bethany R. Knorr of Colby College." History of the Clean Air Act". American Meteorological Society[J].

3. Russell S. Take a stand on AI weapons[J]. Nature, 2015, 521(7553): 415-416.

4. Murphy P. Design capitalism: Design, economics and innovation in the auto-industrial age[J]. She Ji: The Journal of Design, Economics, and Innovation, 2015, 1(2): 140-149.

5. Veloso M. Embrace a robot-human world[J]. Nature, 2015, 521(7553):418-418.

6. Galvan J M. On technoethics[J]. IEEE-RAS Magazine, 2003, 10(4): 58-63.

7. Zhiye Guo, Chengwei Wen. The three inherent ethical dimensions of the technique [J]. A Study of Dialectics of Nature, 2011(5):41-46.

8. Yongyi Lu, Xiaowei Luo. Product, Design, Modern life: The development of industrial design [M]. China Construction Industry Press, 1995.

9. Loy J. eLearning and eMaking: 3D Printing Blurring the Digital and the Physical[J]. Education Sciences, 2014, 4(1): 108-121.

10. Loy J, Canning S, Little C. Industrial design digital technology[J]. Procedia Technology, 2015, 20: 32-38.

11. Candi M. The role of design in the development of technology-based services[J]. Design Studies, 2007, 28(6): 559-583.

12. Tonkinwise C. Ethics by design, or the ethos of things[J]. Design philosophy papers, 2004, 2(2): 129-144.

13. Jonas H. Toward a philosophy of technology[J]. Hastings Center Report, 1979, 9(1): 34-43.

14. Beard C A. Time, Technology, and the creative spirit in political science[J]. American Political Science Review, 1927, 21(1): 1-11.

15. Dearstyne H, Spaeth D. Inside the Bauhaus[M]. 1986.

16. Guoyu Wang. Philosophy of technology turns to ethics in German [J]. Philosophy Research, 2005(5):94-100.

17. Orlikowski W J. The duality of technology: Rethinking the concept of technology in organizations[J]. Organization science, 1992, 3(3): 398-427.

18. Crews D E, Zavotka S. Aging, disability, and frailty: implications for universal design[J]. Journal of physiological anthropology, 2006, 25(1): 113-118. 